\title{
MODEL PROBLEM BASED LEARNING SEBAGAI SALAH SATU CARA MENINGKATKAN HASIL BELAJAR MATA PELAJARAN MEMAHAMI DASAR-DASAR ELEKTRONIKA
}

\author{
Hansi Effendi ${ }^{{ }^{*}}$, Sukardi $^{2}$, Yusnaini $^{3}$ \\ ${ }^{1,2,3}$ Universitas Negeri Padang \\ "hans 79@ft.unp.ac.id
}

\begin{abstract}
This study aims to determine the increase of student learning outcomes in the subject of Understanding the Basics of Electronics using Problem-Based Learning (PBL) model. This research is a quasi-experimental using one group pretest-posttest design. The subjects were students of class X TITL2 SMK Negeri 1 Pariaman enrolled in the academic year 2015/2016 consisting of 40 students. Data were collected by using achievement test consisting of pretest and posttest. Learning outcomes data were analyzed by using the Gain Score formula. The results showed an increase in learning outcomes with a moderate category of students after using the PBL learning model.
\end{abstract}

\section{Pendahuluan}

Sekolah sebagai lembaga pendidikan yang menyelenggarakan pembelajaran mempunyai peranan penting dalam mentransfer pengetahuan dan keterampilan dari guru ke siswa. Peranan tersebut diharapkan dapat menghasilkan manusia-manusia yang berkualitas dan berkompeten dibidangnya, khususnya untuk siswa Sekolah Menengah Kejuruan (SMK). SMK adalah salah satu bentuk satuan pendidikan formal yang menyelenggarakan pendidikan kejuruan pada jenjang pendidikan menengah.

Pendidikan SMK tidak hanya dirancang untuk meningkatkan potensi afektif, kognitif, dan psikomotor peserta didik berkembang secara optimal, tetapi juga dirancang agar dapat menyiapkan peserta didik menjadi manusia produktif yang berjiwa kewirausahaan dan mempunyai kecakapan hidup. SMK mendidik siswa-siswi agar memiliki pengetahuan, keterampilan dan sikap sebagai juru teknik dalam bidang teknologi yang sesuai dengan program studinya masing-masing. Sesuai dengan tujuan SMK yaitu untuk menghasilkan tenaga kerja menengah yang ahli di bidangnya ditunjang dengan hasil belajar yang baik.

Berdasarkan observasi dan wawancara pada bulan Agustus 2015 dengan guru bidang studi mata pelajaran Memahami Dasar-Dasar Elektronika, dijumpai beberapa fenomena yang menghambat tercapainya tujuan pembelajaran, antara lain: (1) penggunaan model pembelajaran yang kurang tepat dalam proses pembelajaran, dimana guru masih sebagai pusat pembelajaran, sehingga berdampak pada siswa yaitu siswa kurang aktif dan tidak kreatif; (2) tidak tersedianya bahan ajar untuk pedoman pembelajaran siswa, di mana yang ada hanya buku pedoman bagi guru pelajaran memahami dasardasar elektronika. Hal ini berdampak kepada siswa yang tidak memiliki kemandirian dalam belajar. 
Dampaknya kepada siswa yaitu ketika siwa diberikan persoalan, siswa menyelesaikannya dengan cara menyalin tugas teman lainnya, pengetahuan atau pemahaman siswa hanya sebatas penyampaian materi dari guru, siswa tidak mampu berfikir kritis dan mengembangkan kemampuan mereka untuk memecahkan masalah. Salah satu akibatnya terlihat dari persentase ketuntasan belajar siswa kelas X TITL 2 pada mata pelajaran MDDE pada Tabel 1.

Tabel 1. Persentase Ketuntasan Belajar Siswa pada Mata Pelajaran MDDE

\begin{tabular}{lccl}
\hline Nilai & Jumlah Siswa & Persentase $(\%)$ & \multicolumn{1}{c}{ Keterangan } \\
\cline { 2 - 4 }$>=75$ & 16 & 40 & Tuntas \\
$<75$ & 24 & 60 & Tidak Tuntas \\
\hline Total & 40 & 100 & \\
\hline
\end{tabular}

Persentase Ketuntasan Belajar Siswa Kelas X TITL 2 pada Semester Ganjil Mata Diklat Memahami Dasar- Dasar Elektronika di SMKN 1 Pariaman, diketahui rata-rata nilai siswa $\geq 75$ adalah $40 \%$ sedangkan persentase rata-rata nilai siswa $<75$ adalah $60 \%$. Rendahnya hasil belajar siswa kelas $\mathrm{X}$ TITL ini karena kurangnya pemahaman siswa terhadap materi pelajaran. Agar tujuan proses pembelajaran dapat tercapai secara efektif dan efesien, harus dilakukan pemilihan metode yang tepat dan sesuai dengan karakter siswa yang lebih mengedepankan kreatifitas dan keaktifan siswa dalam belajar. Maka metode yang tepat untuk diterapkan adalah metode pembelajaran Problem Based Learning.

Pada Pembelajaran Berbasis masalah (PBL) siswa akan belajar secara berkelompok saling menukar pikiran dan ulasan sesama teman. Menurut Duch dalam Riyanto (2009 : 285) "Pembelajaran berbasis masalah adalah suatu model pembelajaran yang menghadapkan peserta didik pada tantangan "belajar untuk belajar". Siswa aktif bekerja sama didalam kelompok untuk mencari solusi permasalahan dunia nyata. Permasalahan ini sebagai acuan bagi peserta didik untuk merumuskan, menganalisis, dan memecahkannya. Lebih lanjut Duch menyatakan bahwa model ini dimaksudkan untuk mengembangkan siswa berpikir kritis, analitis, dan untuk menemukan serta menggunakan sumber daya yang sesuai untuk belajar.

Menurut Trianto (2009:93) karakteristik model pembelajaran PBL adalah sebagai berikut :

a. Berfokus pada keterkaitan antar disiplin

b. Penyelidikan autentik

c. Menghasilkan produk dan memamerkan hasil kerja

d. Kolaborasi.

Secara umum karakteristik model pembelajaran PBL yaitu menyajikan kepada siswa tentang masalah yang autentik. Melalui masalah autentik tersebut, akan memberikan kemudahan kepada para siswa untuk melakukan penyelidikan dan inkuiri. Sedangkan secara khusus, karakteristik model pembelajaran PBL yaitu adanya pengajuan masalah, berfokus pada keterkaitan antar disiplin ilmu, penyelidikan autentik, menghasilkan produk atau karya dan memamerkan produk serta adanya kerjasama.

Langkah-langkah pembelajaran PBL yang telah dirangkum dari pendapat para ahli terdiri dari ; (1) Mengorientasikan peserta didik pada masalah, (2) Mengorganisasikan peserta didik untuk belajar, (3) Membimbing penyelidikan individu dan kelompok, (4) Mengajikan hasil karya serta memamerkannya, (5) Menganalisisdan mengevaluasi proses pemecahan masalah.

Kegiatan dalam model PBL menuntut siswa untuk aktif melakukan penyelidikan dalam menyelesaikan permasalahan dan guru berperan sebagai fasilitator atau pembimbing. Pembelajaran akan dapat membentuk kemempuan berpikir tingkat tinggi (higher order thinking) dan kemampuan siswa untuk berpikir kritis. 


\section{Metode}

Jenis penelitian yang digunakan adalah penelitian eksperimen semu (Quasi Eksperimental). Desain One Group Pretest-Posttest digunakan satu kelompok subjek. Pertama-tama dilakukan pengukuran, lalu dikenakan perlakuan untuk jangka waktu tertentu, kemudian dilakukan pengukuran untuk kedua kalinya. Lebih jelasnya rancangan dalam penelitian ini digambarkan pada Gambar 1.

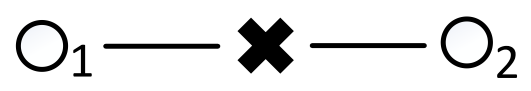

$$
\text { Keterangan: } \begin{aligned}
\mathrm{O}_{1} & =\text { Pre-test } \\
\mathrm{O}_{2} & =\text { Post }- \text { Test } \\
\mathrm{X} & =\text { Treatment (Perlakuan) }
\end{aligned}
$$

\section{Gambar 1. Desain One Group Pretest-Posttest}

Penentuan kelas dilakukan secara acak menggunakan teknik simple random sampling. Sugiyono (2007 : 64 ) mengatakan bahwa : "Simple random sampling adalah pengambilan sampel acak dengan melakukan cara undian terhadap semua populasi".

Penentuan kelas secara acak ini dapat dilakukan berdasarkan rata-rata nilai UTS siswa. Dari hasil simple random sampling tersebut maka terpilih kelas X TITL 2 sebagai objek penelitian dan kelas lain sebagai subjek uji coba soal post-test.

\subsection{Prosedur Penelitian}

Untuk pelaksanaan penelitian maka disusun rencana penelitian agar dapat berjalan dengan baik. Secara umum prosedur penelitian dapat dibagi menjadi tiga tahap yaitu ; persiapan, pelaksanaan, dan tahap akhir. Pada tahap persiapan dilakukan persiapan hal-hal yang mendukung pembelajaran model pembelajaran PBL, mempersiapkan instrument penelitian, melakukan uji coba instrument penelitian, serta menganalisis hasil test. Pada tahap pelaksanaan yaitu penerapan model PBL pada kelas eksperimen. Pada tahap akhir dilakukan pengolahan data subjek penelitian, serta menarik kesimpulan dari hasil yang didapat sesuai dengan teknik analisa data yang dilakukan.

\subsection{Instrumen Penelitian}

Instrument yang digunakan dalam penelitian adalah test hasil belajar dalam bentuk soal objektif. Setelah dilakukan analisis melalui proses uji validitas instrument, reliabilitas, daya pembeda, serta indeks kesukaran, soal uji coba instrument pretest dan posttest yang terdiri dari 40 soal, 35 soal valid, dan 5 soal tidak valid.

\subsection{Teknik Analisis Data}

Data yang diperoleh dari penelitian adalah data hasil belajar siswa pada kelas eksperimen. Teknik analisis data yang digunakan dalam penelitian ini adalah: (a) uji persyaratan analisis dalam bentuk uji normalitas; (b) uji gain score (Hake, 1999). Peningkatan hasil belajar siswa diukur dengan memberikan pre-test dan post-test. Peningkatan hasil belajar dianalisis menggunakan Gain Score untuk melihat tingkat perolehan skor dari penerapan model pembelajaran PBL pada mata pelajaran memahami dasar-dasar elektronika.

\section{Hasil dan Diskusi}

\subsection{Deskripsi Data}

Deskripsi data penelitian ini adalah data hasil belajar siswa pada mata pelajaran memahami dasardasar elektronika. Data awal didapat dari hasil belajar pretest siswa yang berjumlah 40 orang. Nilai pretest siswa berkisar antara 52-84. Kemudian untuk data akhir dilakukan posttest setelah kelas diberi perlakuan dengan menggunakan model pembelajaran PBL. Nilai posttest siswa berkisar antara 70-96. 
Berdasarkan analisis data pretest, diperoleh nilai rata-rata $(\mathrm{X} \overline{)}$ dan simpangan baku (s) sebagai mana dapat dilihat pada Tabel 2. Sedangkan data posttest dapat dilihat pada Tabel 3.

Tabel 2. Data Pretest

\begin{tabular}{lllccc}
\hline Kelas & $\begin{array}{l}\text { Nilai } \\
\text { Tertinggi }\end{array}$ & $\begin{array}{l}\text { Nilai } \\
\text { Terendah }\end{array}$ & X & N & S \\
\cline { 2 - 6 } Total & 80 & 52 & 71,13 & 40 & 6,78 \\
\hline
\end{tabular}

Tabel 3. Data Postest

\begin{tabular}{lllccc}
\hline Kelas & $\begin{array}{l}\text { Nilai } \\
\text { Tertinggi }\end{array}$ & $\begin{array}{l}\text { Nilai } \\
\text { Terendah }\end{array}$ & $\mathrm{X}$ & $\mathrm{N}$ & $\mathrm{S}$ \\
\cline { 2 - 6 } Total & 96 & 70 & 86,63 & 40 & 6,03 \\
\hline
\end{tabular}

\subsection{Analisis Data}

Uji persyaratan analisis yang digunakan untuk penelitian ini adalah uji normalitas. Uji normalitas dilakukan untuk mengetahui apakah sampel penelitian berdistribusi normal atau tidak. Untuk melihat apakah data dari kelas subjek penelitian terdistribusi normal, maka dilakukan uji normalitas dengan menggunakan metode Chi - Kuadrat dengan perhitungan manual. Uji normalitas ini dilakukan pada data kelas ekperimen meliputi hasil Pre-test dan Post-test.

Hasil pengujian diperoleh dari perbandingan harga X2 hitung $<\mathrm{X} 2$ tabel pada subyek penelitian dan pada taraf signifikan $\alpha=0,05$ pada derajat kebebasan $(\mathrm{dk})=7-1=6$. Data menunjukkan bahwa kelas subjek terdistribusi normal.

\subsection{Peningkatan Hasil Belajar}

Berdasarkan uji normalitas posttest didapat bahwa kelas eksperimen terdistribusi normal, sehingga analisa data terjadi peningkatan hasil belajar dan dapat dilanjutkan. Peningkatan hasil belajar siswa dapat diukur dengan membandingkan pretest dan posttest. Peningkatan hasil belajar dianalisis menggunakan rumus Gain Score menurut Hake (1999). untuk melihat peningkatan hasil belajar siswa kelas X TITL2 bisa dilihat pada Tabel 4.

Berdasarkan hasil analisis pada Tabel 4, rata-rata Gain Score secara keseluruhan adalah 0.505. Berarti peningkatan hasil belajar siswa termasuk dalam kategori sedang. Maka dapat disimpulkan bahwa hasil belajar siswa setelah diberi perlakuan dengan menggunakan model pembelajaran PBL mengalami peningkatan. Nilai siswa yang yang peneliti telah analisis dengan rumus Gain Score yang diambil dari satu kali pemberian pretest dan satu kali pemberian posstest.

\section{Kesimpulan}

Berdasarkan analisis data dan pembahasan maka dapat disimpulkan bahwa terdapat peningkatan hasil belajar siswa pada mata diklat memahami dasar-dasar elektronika dengan menggunakan model pembelajaran problem based learning, dengan rata-rata gainscore $=0.505$ dalam kategori sedang. Diharapkan dari perolehan hasil dan data penelitian ini dapat menjadi masukan serta pertimbangan untuk menggunakan model pembelajaran problem based learning untuk meningkatkan hasil belajar siswa. 
Tabel 4. Peningkatan Hasil Belajar Siswa Kelas X TITL2

Mata Pelajaran MDDE

\begin{tabular}{|c|c|c|c|c|}
\hline Subjek & $\begin{array}{l}\text { Nilai } \\
\text { Pretest }\end{array}$ & $\begin{array}{l}\text { Nilai } \\
\text { Posttest }\end{array}$ & GS & Kategori \\
\hline 1 & 64 & 74 & 0.278 & Rendah \\
\hline 2 & 68 & 85 & 0.531 & Sedang \\
\hline 3 & 76 & 85 & 0.375 & Sedang \\
\hline 4 & 64 & 80 & 0.444 & Sedang \\
\hline 5 & 72 & 88 & 0.571 & Sedang \\
\hline 6 & 84 & 90 & 0.500 & Sedang \\
\hline 7 & 72 & 88 & 0.571 & Sedang \\
\hline 8 & 64 & 90 & 0.722 & Tinggi \\
\hline 9 & 72 & 70 & -0.071 & Rendah \\
\hline 10 & 60 & 90 & 0.750 & Tinggi \\
\hline 11 & 64 & 85 & 0.583 & Rendah \\
\hline 12 & 52 & 75 & 0.479 & Sedang \\
\hline 13 & 80 & 85 & 0.250 & Rendah \\
\hline 14 & 76 & 88 & 0.500 & Sedang \\
\hline 15 & 80 & 75 & -0.250 & Rendah \\
\hline 16 & 72 & 85 & 0.464 & Sedang \\
\hline 17 & 68 & 94 & 0.813 & Tinggi \\
\hline 18 & 68 & 80 & 0.375 & Sedang \\
\hline 19 & 72 & 85 & 0.464 & Sedang \\
\hline 20 & 68 & 75 & 0.219 & Rendah \\
\hline 21 & 72 & 88 & 0.571 & Sedang \\
\hline 22 & 76 & 80 & 0.167 & Rendah \\
\hline 23 & 80 & 85 & 0.250 & Rendah \\
\hline 24 & 80 & 85 & 0.250 & Rendah \\
\hline 25 & 80 & 96 & 0.800 & Tinggi \\
\hline 26 & 72 & 80 & 0.286 & Rendah \\
\hline 27 & 68 & 96 & 0.875 & Tinggi \\
\hline 28 & 60 & 85 & 0.625 & Sedang \\
\hline 29 & 56 & 85 & 0.659 & Sedang \\
\hline 39 & 64 & 80 & 0.444 & Sedang \\
\hline 31 & 68 & 96 & 0.875 & Tinggi \\
\hline 32 & 84 & 87 & 0.350 & Sedang \\
\hline 33 & 80 & 88 & 0.400 & Sedang \\
\hline 34 & 76 & 88 & 0.500 & Sedang \\
\hline 35 & 76 & 96 & 0.833 & Tinggi \\
\hline 36 & 72 & 88 & 0.571 & Sedang \\
\hline 37 & 76 & 94 & 0.750 & Tinggi \\
\hline 38 & 72 & 85 & 0.464 & Sedang \\
\hline 39 & 76 & 94 & 0.750 & Tinggi \\
\hline 40 & 68 & 85 & 0.531 & Sedang \\
\hline Rerata & 71,13 & 85,7 & 0,505 & Sedang \\
\hline
\end{tabular}

\section{Referensi}

Arends, Richardi. ( 1997 ). Classroom Instructional Management. New York: The McGraw-Hill Company.

Arikunto, Suharsimi. ( 1991 ). Dasar-dasar evaluasi pendidikan. Jakarta : Bumi Aksara.

Arikunto, Suharsimi. ( 2012 ). Dasar-dasar evaluasi pendidikan. Jakarta : Bumi Aksara. 
Agus, Irianto. (2007). Statistik Konsep Dasar, Aplikasi dan Pengembangannya. Jakarta : Kencana Prenada Media Group.

Dimyati dan Mudjiono. ( 2002 ). Belajar dan Pembelajaran. Jakarta : Rineka Cipta.

Fogarty, R. ( 1997 ). Problem Based Learning and Other Curriculum Models for the Multiple Intelligences Classroom. Arlington Heights, Illinois : Sky Light.

Hake. ( 1999 ). Analyzing Change / Gain Score : (http://www.physics.Indiana.edu) Diakses 05 November 2015.

Hidayat, Rahmat. ( 2010 ). "Penerapan Model Pembelajaran Problem Based Learning Pada Mata Pelajaran Pekerjaan Dasar Elektromekanik Kelas X Jurusan TIPTL Smk Negeri 1 BukitTinggi”. Skripsi. Padang :FT - UNP.

Ibrahim, M. dan Nur, M. ( 2000 ). Pengajaran Berdasarkan Masalah. Surabaya: Unesa University Press.

Joyce, Bruce \& Marsha Weil. ( 1980 ). Models of Teaching, Fifth Edition. USA: Allyn and Bacon A Simon \& Scuster Company.

Lufri. ( 2006 ). Konsep, Teori, Pendekatan, Metode, dan Strategi Dalam Pendidikan dan Pembelajaran. Padang :UNP.

Panjaitan, Bernalam Siharuli. ( 2011 ). "Penerapan Pembelajaran Problem Based Learning untuk Meningkatkan Hasil Belajar Alat Ukur Listrik dan Elektronika di Smk Taman Siswa Tebing Tinggi”. Skripsi. Padang : FT - UNP.

Paul Eggen and Don Kauchak. ( 2012 ). Strategi dan Model Pembelajaran. Jakarta Barat :PT Indeks.

Restiono, Awal. ( 2013 ). "Penerapan Model Problem Based Learning Untuk Mengembangkan Aktifitas Berkarakter dan Meningkatkan Pemahaman Konsep Siswa Kelas XI Jurusan Fisika". Skripsi. Semarang : FMIPA - UNS.

Riyanto, Yatim. ( 2010 ). Paradigma Baru Pembelajaran. Jakarta: Kencana.

Rusman. ( 2010 ). Model - Model Pembelajaran. Jakarta: PT. RajaGrafindo Persada.

Riduwan. (2006). Belajar Mudah Penelitian Untuk Guru, Karyawan Dan Peneliti

Pemula. Bandung: Alfabeta.

Sudjana, Nana. ( 2011 ). Penilaian Hasil Proses Belajar Mangajar. Bandung : PT Remaja Rosdakarya.

Silitonga, Oliver Putra. (2009). "Penerapan model Problem Based Learning (PBL) untuk meningkatkan hasil belajar dasar dan pengukuran listrik di Smk Negeri 2 Sawahlunto". Skripsi. Padang : FT - UNP

Slavin, R. E. (1997). Educational Psychology Theory, Research, and Practice, Fifth Edition. Massachusetts : Allyn and Bacon.

Suyanti, Dwi Retno. (2010). Strategi Pembelajaran Kimia. Yogyakarta: Graha Ilmu

Sudjana, Nana. ( 2008 ). Dasar-Dasar Proses Belajar Mengajar. Bandung : Sinar Baru Algensindo.

Sugiyono. (2012). Statistika Untuk Penelitian. Bandung : Alfabeta.

Sumadi. ( 2010 ). Metodelogi Penelitian. Jakarta : Rajawali Pers.

Trianto. ( 2009 ). Mendesain Model Pembelajaran Inovatif - Progresif. Jakarta: Kencana

Trianto. ( 2010 ). Mendesain Model Pembelajaran Inovatif - Progresif. Jakarta: Kencana.

Winkel, W.S. ( 1996 ). Psikologi Pendidikan. Jakarta: Gramedia Mediasarana Indonesia. 